einer unipolaren Depression ähnlicher sein könnten und zudem schwerer in ihrer Funktionalität eingeschränkt sind als Bipolar-I-Patienten [1, 2]. Interessant ist zudem, dass das von SESTD1 kodierte Protein eine Rolle im Phospholipidstoffwechsel spielt, der sowohl bei der Pathogenese der bipolaren Störung als auch bei der Wirkungsweise von Lithium relevant zu sein scheint. Eine Replikation dieses interessanten Befundes in unabhängigen Stichproben ist natürlich noch nötig, um die Relevanz der Ergebnisse zu validieren. Eine klinische Anwendung als Therapieresponsemarker ist aber aufgrund des seltenen Vorkommens der Genvariante nicht realisierbar, wie die Autoren selbst schreiben. Hier könnten andere Genvarianten aus einer kürzlichen Untersuchung von Hou et al., die mit Lithiumresponse assoziiert gezeigt wurden und häufiger vorkommen, hinsichtlich der Entwicklung von prädiktiven Biomarkern für Therapieresponse nützlicher sein [3].
Referenzen:

1. Vinberg M et al. J Affect Disord 2016; pii: S0165-0327(16)30911-9 [Epub ahead of print]

2. Minichino A et al. Bipolar Disord 2016; 18: $591-601$

3. Hou Let al. Lancet 2016: 387: 1085 -93

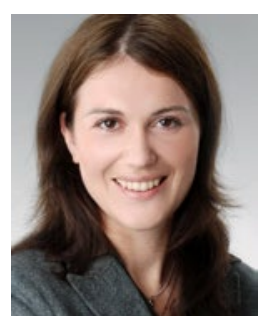

Dr. med. Sarah Kittel-Schneider, Frankfurt am Main

Leitende Oberärztin, Klinik für Psychiatrie,

Psychosomatik und Psychotherapie,

Universitätsklinikum Frankfurt am Main

E-Mail: Sarah.Kittel-Schneider@kgu.de

\title{
Neurologische Funktion positiv beeinflusst
}

Fragestellung: Kann mit menschlichen neuronalen Stammzellen bei Patienten mit chronischen neurologischen Defiziten nach einem ischämischen Insult das funktionelle Defizit verbessert werden?

Hintergrund: Bei vielen Patienten verbleiben nach einem Schlaganfall neurologische Defizite, die sich auch mit einer intensiven krankengymnastischen, neurokognitiven oder Sprachtherapie nicht vollständig zurückbilden. In Tierexperimenten sind neuronale Stammzellen vier Wochen nach dem akuten Ereignis therapeutisch wirksam. In histologischen Schnitten kann sowohl eine Neubildung von Gefäßen wie Neuronen im ischämischen Areal nachgewiesen werden. Dieses Konzept sollte jetzt erstmals bei Menschen nach ischämischem Insult untersucht werden.

Kalladka D, Sinden J, Pollock K et al. Human neural stem cells in patients with chronic ischaemic stroke (PISCES): a phase 1, first-in-man study. Lancet 2016; 20: $388: 787-96$
Patienten und Methodik: CTX0E03 sind menschliche neuronale Stammzellen, die zu einem Medikament entwickelt wurden. Es handelte sich um eine offene Dosisfindungsstudie. Eingeschlossen wurden Männer im Alter von 60 oder älter, mit einer Behinderung nach einem Schlaganfall auf der NIHSS von $\geq 6$ und einer modifizierten Rankin-Skala zwischen 2 und 4. Der Einschluss erfolgte sechs bis 60 Monate nach einem ischämischen Insult. Bei den Patienten wurden stereotaktisch Dosen von zwei, fünf, zehn oder 20 Millionen Stammzellen in das ipsilaterale Putamen injiziert. Dann wurden die Patienten über zwei Jahre nachverfolgt. Der primäre Endpunkt war ein Sicherheitsendpunkt.

Ergebnisse: Zwischen September 2010 und Januar 2013 wurde bei elf Männern CTX-DP stereotaktisch injiziert. Der mittlere NIHSS vor Implantation war 7 und die mittlere Zeit vom Schlaganfall bis zur Implantation waren 29 Monate. Drei der Männer hatten subkortikale Infarkte und sieben hatten rechtshemisphärische Infarkte. Bei keinem der Patienten kam es zu immunologischen Nebenwirkungen. Nach zwei Jahren kam es zu einer Verbesserung des NIHSS zwischen null und fünf Punkten mit einem Median von zwei Punkten.

Schlussfolgerungen: Eine einmalige intrazerebrale Implantation von CTX-DP mit bis zu 20 Millionen Stammzellen führte zu keinen Nebenwirkungen und hat möglicherweise eine positive Auswirkung auf die neurologischen Funktionen.

\section{- Kommentar von Hans-Christoph Diener, Essen}

\section{Vielleicht einfach der Spontanverlauf der neurologischen Ausfälle?}

Obwohl hochrangig publiziert, handelt es sich hier um eine sehr kleine Sicherheitsstudie. Die von den Autoren unterstellte Besserung der neurologischen Ausfälle durch die Stammzellimplantation kann aber auch sehr wohl der Spontanverlauf der neurologischen Ausfälle sein. Zumindest sind in der Studie keine schwerwiegenden lokalen Nebenwirkungen in der
Bildgebung beobachtet worden. Ob diese wenigen Daten rechtfertigen, eine größere Studie am Menschen durchzuführen, ist weiterhin zweifelhaft. Wahrscheinlich macht es sehr viel mehr Sinn, auch im Zeitintervall nach einem ischämischen Insult nochmals intensiv Krankengymnastik, Sprach- und Beschäftigungstherapie einzusetzen. 